Article

\title{
Interaction of Several Toxic Heterocarbonyl Gases with Polypyrrole as a Potential Gas Sensor
}

\author{
Francisco C. Franco Jr. (D) \\ Chemistry Department, De La Salle University, 2401 Taft Avenue, Manila 0922, Philippines; \\ francisco.franco@dlsu.edu.ph; Tel.: +63-2-85360230
}

Received: 4 August 2020; Accepted: 10 September 2020; Published: 14 September 2020

check for updates

\begin{abstract}
The interactions of the toxic heterocarbonyl gases phosgene, carbonyl fluoride, formaldehyde, carbonyl sulfide, and acetone with polypyrrole as a toxic heterocarbonyl gas sensor, were extensively studied by density functional theory (DFT). The Becke 3-parameter, Le $\mathrm{e}^{\mathrm{e}}$-Yang-Parr (B3LYP) exchange-correlation functional methods were first tested against several high-level DFT methods employing the Dunning's double- $\zeta$ and triple- $\zeta$ basis sets and were found to be sufficient in describing the non-covalent interactions involved in this study. The interaction of pyrrole with the heterocarbonyl gases resulted in changes in the structure and optoelectronic properties of the polymer and it was observed that acetone and formaldehyde had the strongest H-bonding interaction with polypyrrole, while the interaction of phosgene and formaldehyde resulted in the lowest energy gap and may result in its high sensitivity towards these gases. The UV-Vis absorption revealed significant red-shifted first singlet excited states ( $\left.E_{\text {excited, 1st }}\right)$ of the complexes and follows the same trend as the $E_{\mathrm{Gap}}$ values. It is shown that the $E_{\text {excited, 1st }}$ was due to the $\pi\left(\mathrm{HOMO}_{\mathrm{Py}}\right) \longrightarrow \pi^{*}\left(\mathrm{LUMO}_{\mathrm{HC}}\right)$ transitions and the excited state at maximum absorption ( $\left.E_{\text {excited, max }}\right)$ was due to the $\pi\left(\mathrm{HOMO}_{\mathrm{Py}}\right) \longrightarrow \pi^{*}\left(\mathrm{LUMO}_{\mathrm{Py}}\right)$ transitions. This study demonstrates the potential sensitivity and selectivity of polypyrrole as a toxic heterocarbonyl sensor.
\end{abstract}

Keywords: gas sensors; chemiresistor; conducting polymer; optoelectronic properties; density functional theory

\section{Introduction}

Heterocarbonyl gases such as phosgene, carbonyl fluoride, formaldehyde, carbonyl sulfide, and acetone are well-known toxic compounds and may cause numerous health problems, especially through chronic exposure. The effects of these compounds may range from mild irritation, and allergy to more serious ones, including asthma, cancer, genetic deficiency, damage to organs, and others [1-3]. Phosgene is a colorless gas and a highly toxic industrial gas that is very reactive and poses a significant public health risk. In aqueous media, it hydrolyzes to form hydrochloric acid and carbon dioxide. Phosgene is widely used in the industry for various chemical processes involving plastics, pesticides, dyes, pharmaceuticals. It was even used during World War I as a chemical weapon, resulting in a large number of deaths. Inhalation of phosgene gas results in very harmful effects on the lungs and respiratory tract. When inhaled excessively, the person may suffer from pulmonary edema or pulmonary emphysema, and even death [1,4]. Carbonyl fluoride is also a colorless and highly toxic gas. This gas may undergo hydrolysis in water, producing hydrofluoric acid and carbon dioxide. It is primarily used as an intermediate for the production of organic fluorine compounds. Similar to phosgene, the production of acid products may be the main cause of toxicity in the body. Exposure to this gas may lead to irritation, inflammation, pulmonary congestion, and may lead to death $[2,5,6]$. Formaldehyde is a flammable and colorless gas that is characterized by its distinct strong unpleasant odor. This compound is typically found in household products, resins, building materials, preservatives, 
agricultural products, and cosmetics. Exposure to this gas may affect the eye, skin, throat, nose, and may lead to very serious conditions including asthma and cancer $[3,7,8]$. Carbonyl sulfide is a flammable colorless gas with an unpleasant odor similar to other sulfur-compounds. It is the most abundant sulfur compound present naturally in the atmosphere and emitted from environmental processes [9]. It was also reported that carbonyl sulfide is produced endogenously in humans and may help detect the levels of bilirubin in the body and acute rejection of lung transplants [10]. This gas is typically used as an intermediate of sulfur-containing herbicides and as a fumigant in the agricultural industry [9]. Studies suggest that carbonyl sulfide may reversibly impair male fertility under repeated exposure and could be neurotoxic at high levels and prolonged exposure [10]. Acetone is a colorless, volatile, and flammable solvent extensively used in the industry for a wide range of purposes. Although less toxic than the gases mentioned above, acetone is present in the atmosphere and may undergo photolysis producing harmful radicals. High doses of acetone inhalation may lead to respiratory irritation [11-13]. Due to the harmful effects of these compounds, easily detecting these toxic gases is needed to mitigate the health risks that these compounds pose. These heterocarbonyl compounds are typically present as contaminants or residues of each other, since one can be produced using another as a starting material. Carbonyl sulfide could be synthesized from the reaction of phosgene with cadmium [14], while carbonyl sulfide can react with chlorine to produce phosgene [15]. Phosgene can also react with anhydrous hydrogen fluoride to produce carbonyl fluoride, and the typical contaminants in carbonyl fluoride are phosgene and carbonyl sulfide [16]. On the other hand, a typical impurity in acetone is formaldehyde [17], and acetone may be reacted with formaldehyde to produce resins [18]. Thus, both sensitivity and selectivity should be addressed for a potential gas sensor to these compounds.

Various gas sensors have been used for the detection of toxic gases and the materials are mostly based on metal oxide/inorganic semiconductors and conducting organic polymers [19-22]. Conducting organic polymers offer many advantages over inorganic semiconductors due to its low-cost, simple method of fabrication, stability, lightweight, flexibility, sensitivity, and easily tuned optoelectronic properties $[20,23,24]$. Organic conducting polymers are versatile materials with a wide range of applications which include solar cells, batteries, optoelectronic materials, capacitors, actuators, fuel cells, actuators, and sensors [25-32]. Previously reported organic conducting polymers for gas-sensing applications to include polyaniline, polyacetylene, polythiophene, and polypyrrole [33-36]. Polypyrrole, in particular, is a well-studied and important gas sensor due to its reported $\mathrm{pH}$ sensitivity, stability, and high conductivity [37]. Many simple gas analytes have been previously studied experimentally for polypyrrole, including $\mathrm{NH}_{3}, \mathrm{NO}_{2}, \mathrm{NO}_{3}{ }^{-}, \mathrm{CO}_{2}, \mathrm{CH}_{4}, \mathrm{H}_{2}$, and $\mathrm{H}_{2} \mathrm{O}_{2}$ [33,38-42]. Polypyrrole was used to detect methanol against ethanol and propanol by preparing nanostructures in the presence of perchlorate or $p$-toluene sulfonate dopants using constant current electrodeposition and was observed to be highly sensitive and selective to methanol [43]. A highly sensitive and selective DMSO sensor was also prepared using nano-structured polypyrrole in the presence of various anionic dopants [44]. Polypyrrole has also been previously used as a sensitive and selective sensor to detect a mixture of volatile organic compounds (VOCs) such as pyridine derivatives, acetonitrile, DMSO, alcohols, aldehydes, ketone, benzene derivatives, and alkanes. In the study, the change in the resistances of the pyrrole-coated was measured and the analytes were quantified [45]. In another study, polypyrrole was successfully used as a sensitive sensor and was synthesized on an $\mathrm{Au} / \mathrm{Al}_{2} \mathrm{O}_{3}$ surface to detect acetone. The polypyrrole films on the surface were prepared by chemical oxidation-casting, chemical vapor deposition, and impregnated oxidation methods [46]. Polypyrrole has also been used to detect aromatic hydrocarbons benzene, ethyl benzene, toluene, trimethylbenze, alcohols, acetone, acetonitrile, chloroform, and carbon disulfide. The polypyrrole was deposited and polymerized on the surface of a commercial polymer fiber and doped with dodecyl sulfate as an anion dopant [47]. Polypyrrole was even used as a liquefied petroleum gas sensor by combining $\mathrm{Nb}_{2} \mathrm{O}_{5}$ nanoparticles with polypyrrole and forming a nanocomposite and was demonstrated to have good sensing capabilities and stability for over a month [48]. The studies above demonstrate the capability of polypyrrole as a gas sensor for a wide range of organic compounds with varying functional groups. However, studies involving the 
use of polypyrrole as a gas sensor for the toxic carbonyl compounds mentioned above has been limited to date. Theoretical studies on the interaction of these toxic carbonyl gases with polypyrrole may help to understand its potential sensitivity and selectivity as a gas sensor and guide future experiments.

Polypyrrole has been previously studied theoretically as a gas sensor for the detection of various analytes including $\mathrm{HCN}, \mathrm{SO}_{2}, \mathrm{NH}_{3}, \mathrm{H}_{2} \mathrm{O}, \mathrm{CO}, \mathrm{CH}_{4}, \mathrm{CO}_{2}, \mathrm{NO}_{3}{ }^{-}$, aldehydes, and ketones [49-56]. The nanocomposite of polypyrrole- $\mathrm{TiO}_{2}$ has also been studied theoretically for potential photocatalysis applications [57,58]. In these studies, the method of choice was density functional theory (DFT) methods, which is a highly used method for understanding the electronic and optical properties of materials at the molecular level considering the balance between accuracy and computational costs. DFT has been used extensively in the literature studying conducting polymers for various applications, and, despite its limitations, provides insights into the meaning and consistency of the calculated values and trends with the experiments [59-67]. In particular, the Becke three-parameter exchange, Lee, Yang, and Parr (B3LYP) hybrid functional [68] is one of the most common functionals used in calculations involving structure-property relationships between the changes in the geometry of the polymers and its electronic structure, even though it has been shown that the B3LYP functional is not suitable for non-covalent interactions [69-72]. Therefore, the appropriate method for describing polymer-analyte interactions must also be tested against high-level DFT methods for better accuracy and prediction of properties, which may aid in the development of polypyrrole as a potential gas sensor.

When a conducting sensing polymer is exposed to an analyte, various chemical and physical response mechanisms occur, including conformational changes, charge transfer/redox processes, and electronic structure changes, which could result in changes in its conductivity and could be addressed by DFT calculations. In this study, the interaction of the toxic heterocarbonyl gases phosgene, carbonyl fluoride, formaldehyde, carbonyl sulfide, and acetone with polypyrrole as a gas sensor was studied by DFT. First, the appropriate B3LYP method and basis set for geometry optimizations and energy calculations were determined by comparing several B3LYP methods with several high-level DFT methods. Second, the structural changes (bond lengths, bond angles, dihedral angles), vibrational modes, electron charge transfers, and interaction energies of polypyrrole with heterocarbonyl gases were analyzed and compared between the various gases. Finally, the effects of these changes were then used to explain the electronic and optical properties of each polypyrrole-gas complex and the potential of polypyrrole as a sensitive and selective gas sensor was demonstrated. To the best of our knowledge, this is the first demonstration of polypyrrole as a potential gas sensor for phosgene, carbonyl fluoride, and carbonyl sulfide.

\section{Materials and Methods}

Figure 1 shows the chemical structures of the polypyrrole (9Py), represented as nine units of pyrrole monomers, interacting with several heterocarbonyl gases $(\mathrm{HC})$ : phosgene $(\mathrm{CCl})$, carbonyl fluoride (CF), formaldehyde (CH), carbonyl sulfide (CS), and acetone (CMe), used in this study. In gas sensing experiments, the polymer films are deposited on the surface of the electrode [24,73] and gas molecules mostly interact on the surface and in the bulk of the long polymer chain, as demonstrated in previous polymer-based gas sensor calculations [51,74,75]. Thus, in this study, polypyrrole was represented by a nine-unit-long oligomer, and the gas analyte was placed in the middle of the chain to reduce the interaction of the gas molecules with the edges of the polymer. All DFT calculations were carried out using the Gaussian16 computational package [76]. Geometry optimizations and energy calculations were performed using the B3LYP functional in the gas phase. The coordinates of the optimized geometries are presented in the Supplementary Material, Table S1. As mentioned, the B3LYP functional has limitations in describing non-covalent interactions due to the presence of dispersion forces. Nevertheless, the B3LYP functional is arguably the most popular functional in theoretical studies involving the sensing capability of polypyrrole and other conducting polymers $[49,51,53,55]$. However, several methods may be carried out to reduce these errors, such as counterpoise (CP) [77] and Grimme's dispersion [69-71] corrections. In a recent study on 21 small bimolecular van der Waals organic complexes, 
it was demonstrated that the functionals B97-D3, B3LYP-D3 and M05-2X functionals with Dunning's aug-cc-pVDZ basis set are suitable for predicting the equilibrium geometries of non-bonded complexes [78]. In another study on the performance of various DFT functionals on the non-covalent interaction of organic complexes with the double- $\zeta$ (aug-cc-pVDZ) and triple- $\zeta$ (aug-ccpVTZ) basis sets by Dunning, it was shown that, for the double- $\zeta$ basis, the B97-D2, B97-D3, M06-2X, and M05-2X functionals are recommended. While for the triple- $\zeta$ basis, the $\omega$ B97X-D, B2PLYPD3, B3LYP-D3, and M06-2X functionals are recommended [79]. Therefore, these high-level methods were tested against several B3LYP methods with and without the Grimme's and CP corrections together with various basis sets for $1 \mathrm{Py}-\mathrm{CH}$ to determine the appropriate level for the polypyrrole-carbonyl complexes in this study.

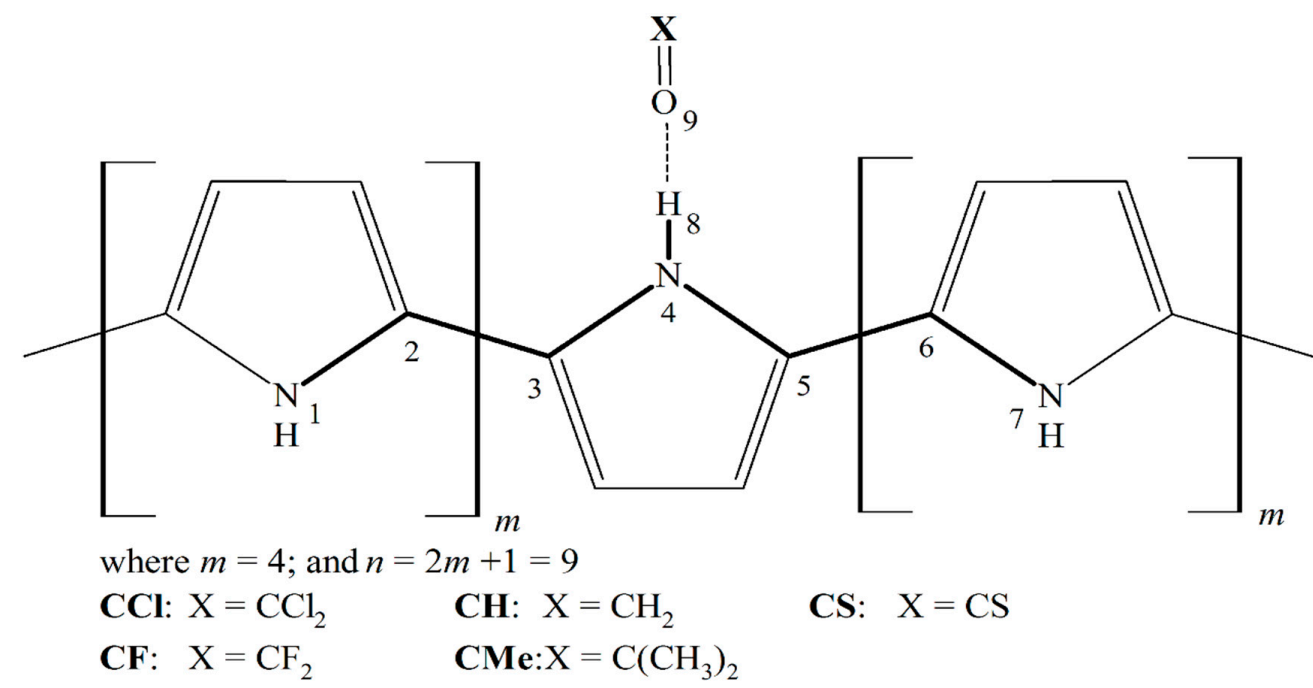

Figure 1. Chemical structures of the (9Py-HC) pyrrole-heterocarbonyl gas complexes and the numbering scheme used in this study.

The equilibrium geometries of the polypyrrole-carbonyl (9Py-HC) complexes in the gas phase were determined by DFT using the B3LYP functional together Grimme's electron dispersion correction (D3) with modification of damping $(B J)$ and $6-31+G(d, p)$ as the basis set, B3LYP-D3(BJ)/6-31+G(d,p), followed by vibrational analysis at the same level to ensure that the structures are at the local minima. Energy calculations were done using the same level with an additional counterpoise correction (CP), DFT/B3LYP-D3(BJ)-CP/6-31+G(d,p) to reduce the basis set superposition error (BSSE). Interaction energies were calculated as

$$
E_{\text {int }}=E_{\text {complex }}-E_{\mathrm{Py}}-E_{\mathrm{HC}}
$$

where $E_{\text {complex }}, E_{\mathrm{Py}}$, and $E_{\mathrm{X}}$ are the total energies of the pyrrole-heterocarbonyl (Py-HC) complexes, isolated pyrrole (9Py), and isolated heterocarbonyl gas (HC), respectively. The UV-Vis spectrum was simulated by TDDFT calculations at the B3LYP/6-31+G(d,p) level. The structures were viewed using Chemcraft [80], while the molecular orbitals were shown using GaussView6 [81]. The NBO population analysis was carried out using the NBO program [82], while the UV-Vis spectrum and the density of states were determined using the GaussSum package [83].

\section{Results and Discussion}

\subsection{Determination of the Appropriate B3LYP Method and Basis Set against Several High-Level DFT Methods}

Table 1 shows the structural parameters obtained for 1Py-CH using several B3LYP methods: B3LYP-D3(BJ), B3LYP, B3LYP-CP, and B3LYP-D3(BJ)-CP, with various basis sets: 6-31+G(d,p), 6-311+G(d,p), aug-cc-pVDZ, and aug-cc-pVTZ. These B3LYP methods and basis sets were tested against the B97D3, M05-2X, and $\omega$ B97xD methods with aug-cc-pVDZ as the basis set. It can be observed that the distances between $\mathrm{N}_{4}$ and $\mathrm{H}_{8}$ are the same for all combinations, while the $\mathrm{C}_{3} \mathrm{~N}_{4} \mathrm{C}_{5}$ angles are 
virtually the same for all methods. Significant differences were observed for the hydrogen-bonded atoms $\mathrm{H}_{8}$ and $\mathrm{O}_{9}$, and the angle between the hydrogen-bonded atoms $\mathrm{C}_{3}, \mathrm{~N}_{4}$, and $\mathrm{C}_{5}$. The B97D3, M05-2X, and $\omega$ B97xD combinations have $\mathrm{H}_{8}-\mathrm{O}_{9}$ distances ranging from 2.10 to $2.17 \AA$, with an average of $2.13 \AA$, while the $\mathrm{C}_{3} \mathrm{~N}_{4} \mathrm{C}_{5}$ angles ranged from $134.0^{\circ}$ to $142.4^{\circ}$, with an average of $139.2^{\circ}$. For the B3LYP methods, the B3LYP and B3LYP-CP combinations generated shorter $\mathrm{H}_{8}-\mathrm{O}_{9}$ distances and higher $\mathrm{C}_{3} \mathrm{~N}_{4} \mathrm{C}_{5}$ angles. On the other hand, The B3LYP-D3(BJ) and B3LYP-D3(BJ)-CP combinations generated similar $\mathrm{H}_{8}-\mathrm{O}_{9}$ distances (2.11 and $2.12 \AA$ ) and virtually the same $\mathrm{C}_{3} \mathrm{~N}_{4} \mathrm{C}_{5}$ angles $\left(139.5^{\circ}\right.$ to $\left.142.6^{\circ}\right)$. Thus, the B3LYP-D3(BJ)/6-31+G(d,p), less computationally intensive than B3LYP-D3(BJ)-CP, was used for the $9 \mathrm{Py}-\mathrm{HC}$ geometry optimizations.

Table 1. Structural parameters from the equilibrium geometries of $1 \mathrm{Py}-\mathrm{CH}$ using several B3LYP methods and basis sets in the gas phase against several high-level density functional theory (DFT) methods with an aug-cc-pVDZ basis set.

\begin{tabular}{cccccc}
\hline & & \multicolumn{2}{c}{$\mathbf{d}(\mathbf{A})$} & \multicolumn{2}{c}{$\boldsymbol{\theta}\left(^{\circ}\right)$} \\
\cline { 3 - 6 } Method & Basis Set & $\mathbf{H}_{\mathbf{8}} \cdot \mathbf{O}_{\mathbf{9}}$ & $\mathbf{N}_{\mathbf{4}}-\mathbf{H}_{\mathbf{8}}$ & $\mathbf{N}_{\mathbf{4}} \mathbf{H}_{\mathbf{8}} \mathbf{O}_{\mathbf{9}}$ & $\mathbf{C}_{\mathbf{3}} \mathbf{N}_{\mathbf{4}} \mathbf{C}_{\mathbf{5}}$ \\
\hline B3LYP-D3(BJ) & 6-31+G(d,p) & 2.11 & 1.01 & 140.2 & 109.7 \\
& 6-311+G(d,p) & 2.12 & 1.01 & 139.5 & 109.7 \\
& aug-cc-pVDZ & 2.05 & 1.01 & 147.0 & 109.8 \\
& aug-cc-pVTZ & 2.07 & 1.01 & 146.0 & 109.7 \\
\hline B3LYP & 6-31+G(d,p) & 2.06 & 1.01 & 165.5 & 109.6 \\
& 6-311+G(d,p) & 2.07 & 1.01 & 168.0 & 109.5 \\
\hline B3LYP-CP & 6-31+G(d,p) & 2.09 & 1.01 & 164.3 & 109.6 \\
& 6-311+G(d,p) & 2.10 & 1.01 & 167.4 & 110.0 \\
\hline B3LYP-D3(BJ)-CP & 6-31+G(d,p) & 2.11 & 1.01 & 142.6 & 109.7 \\
& 6-311+G(d,p) & 2.12 & 1.01 & 140.6 & 109.7 \\
\hline B97D3 & aug-cc-pVDZ & 2.12 & 1.01 & 142.4 & 110.0 \\
M05-2X & aug-cc-pVDZ & 2.17 & 1.01 & 134.0 & 109.9 \\
$\omega$ (BD97xD & aug-cc-pVDZ & 2.10 & 1.01 & 141.3 & 109.8 \\
\hline
\end{tabular}

Table 2 shows the interaction energies using several B3LYP methods: B3LYP-D3(BJ) and B3LYP-D3(BJ)-CP with the 6-31+G(d,p) and 6-311+G(d,p) basis sets from the B3LYP-D3(BJ)/6-31G+(d,p) optimized structure. These B3LYP combinations were then tested against the B97D3, B97D2, M05-2X, and M06-2X methods with aug-cc-pVDZ as the basis set, and M06-2X, $\omega$ B97xD, B2PLYPD3, and B3LYP-D3(BJ) methods with aug-cc-pVTZ as the basis set. The interaction energies of the DFT methods with the Dunning's correlation consistent basis sets were observed to range from -5.35 to $-6.05 \mathrm{kcal} / \mathrm{mol}$, with an average of $-5.69 \pm 0.24 \mathrm{kcal} / \mathrm{mol}$. The B3LYP-D3(BJ) method was observed to overestimate the magnitude of the interaction energies, $-6.00 \mathrm{kcal} / \mathrm{mol}$ for $6-31+\mathrm{G}(\mathrm{d}, \mathrm{p})$ and $-6.08 \mathrm{kcal} / \mathrm{mol}$ for $6-311+G(d, p)$, but was in line with the counterpoise-corrected B3LYP-D3(BJ)-CP method, where the $6-31+G(d, p)$ and $6-311+G(d, p)$ basis sets have very similar values of -5.74 and $-5.70 \mathrm{kcal} / \mathrm{mol}$, respectively. The B3LYP-D3(BJ)-CP/6-31+G(d,p) was then utilized for the 9Py-HC energy calculations.

Table 2. Interaction energies of $1 \mathrm{Py}-\mathrm{CH}$ using several B3LYP methods against high-level DFT methods with aug-cc-pVDZ and aug-cc-pVTZ basis sets.

\begin{tabular}{ccc}
\hline Method & Basis Set & $\boldsymbol{E}_{\text {int }}$ (kcal/mol) \\
\hline B97D3 & aug-cc-pVDZ & -5.48 \\
B97D2 & aug-cc-pVDZ & -5.35 \\
M05-2X & aug-cc-pVDZ & -6.01 \\
M06-2X & aug-cc-pVDZ & -6.05 \\
& aug-cc-pVTZ & -5.70 \\
$\omega$ B97xD & aug-cc-pVTZ & -5.53 \\
B2PLYPD3 & aug-cc-pVTZ & -5.70 \\
B3LYP-D3(BJ) & aug-cc-pVTZ & -5.70 \\
& $6-31+\mathrm{G}(\mathrm{d}, \mathrm{p})$ & -6.08 \\
& $6-311+\mathrm{G}(\mathrm{d}, \mathrm{p})$ & -6.00 \\
B3LYP-D3(BJ)-CP & $6-31+\mathrm{G}(\mathrm{d}, \mathrm{p})$ & -5.74 \\
& $6-311+\mathrm{G}(\mathrm{d}, \mathrm{p})$ & -5.70 \\
\hline
\end{tabular}




\subsection{Structural Parameters for the 9Py-HC Complexes}

The structural changes in 9Py upon its interaction with the HC gases are shown in Table 3. It was previously shown in previous studies with polypyrrole $[52,55,56]$ that these structural parameters are virtually the same for shorter chain lengths, thus, only $n=9$ units (9Py) to represent infinite chain length were carried out in this study. The length between the hydrogen-bonded (H-bond) atoms, $\mathrm{H}_{8}-\mathrm{O}_{9}$, showed that the shortest distance was observed for 9Py-CMe (1.929 $⿱$ ) followed by $9 \mathrm{Py}-\mathrm{CH}$ $(1.981 \AA), 9 \mathrm{Py}-\mathrm{CCl}(2.176 \AA), 9 \mathrm{Py}-\mathrm{CF}(2.194 \AA)$, and the longest for 9Py-CS $(2.352 \AA)$. The angle between the hydrogen bond donor $\left(\mathrm{N}_{4}\right)$, hydrogen atom $\left(\mathrm{H}_{8}\right)$, and hydrogen bond acceptor $\left(\mathrm{O}_{9}\right), \mathrm{N}_{4} \mathrm{H}_{8} \mathrm{O}_{9}$ angle, is closest to linearity in $9 \mathrm{Py}-\mathrm{CMe}\left(163.9^{\circ}\right)$, followed by $9 \mathrm{Py}-\mathrm{CH}\left(160.2^{\circ}\right), 9 \mathrm{Py}-\mathrm{CCl}\left(152.4^{\circ}\right), 9 \mathrm{Py}-\mathrm{CF}$ $\left(150.0^{\circ}\right)$ and lastly $9 \mathrm{Py}-\mathrm{CS}\left(134.5^{\circ}\right)$. The trend could indicate that $\mathrm{CMe}$ has the strongest $\mathrm{H}-\mathrm{bond}$ interaction with 9Py and the weakest interaction occurs with CS. Moreover, due to the interaction of the gases, the weakening of the $\mathrm{N}_{4}-\mathrm{H}_{8}$ bond was observed, where the largest increase in $\mathrm{N}_{4}-\mathrm{H}_{8}$ bond length was observed with 9Py-CMe and has the opposite trend with the shortening of H-bond lengths.

Table 3. Structural parameters for the optimized 9Py-HC complexes at the B3LYP-D3(BJ)/6-31+G(d,p) level.

\begin{tabular}{cccccccc}
\hline \multicolumn{2}{c}{$\mathbf{d}(\mathbf{\AA})$} & \multicolumn{2}{c}{$\boldsymbol{\theta}\left(^{\circ}\right)$} & \multicolumn{4}{c}{$\boldsymbol{\Phi}\left(^{\circ}\right)$} \\
\hline 9Py-HC & $\mathbf{H}_{\mathbf{8}} \cdot \mathbf{O}_{\mathbf{9}}$ & $\mathbf{N}_{\mathbf{4}}-\mathbf{H}_{\mathbf{8}}$ & $\mathbf{N}_{\mathbf{4}} \mathbf{H}_{\mathbf{8}} \mathbf{O}_{\mathbf{9}}$ & $\mathbf{C}_{\mathbf{3}} \mathbf{N}_{\mathbf{4}} \mathbf{C}_{\mathbf{5}}$ & $\mathbf{N}_{\mathbf{1}} \mathbf{C}_{\mathbf{2}} \mathbf{C}_{\mathbf{3}} \mathbf{N}_{\mathbf{4}}$ & $\mathbf{C}_{\mathbf{2}} \mathbf{C}_{\mathbf{3}} \mathbf{N}_{\mathbf{4}} \mathbf{C}_{\mathbf{5}}$ & $\mathbf{N}_{\mathbf{4}} \mathbf{C}_{\mathbf{5}} \mathbf{C}_{\mathbf{6}} \mathbf{N}_{\mathbf{7}}$ \\
\hline 9Py & - & 1.008 & - & 110.6 & 157.7 & -179.8 & -157.7 \\
9Py-CCl & 2.176 & 1.011 & 152.4 & 110.3 & 161.5 & -179.2 & -146.2 \\
9Py-CF & 2.194 & 1.011 & 150.0 & 110.3 & 161.3 & -179.2 & -148.8 \\
9Py-CH & 1.981 & 1.017 & 160.2 & 110.4 & 177.6 & -178.9 & -153.6 \\
9Py-CS & 2.352 & 1.009 & 134.5 & 110.4 & 159.9 & -179.2 & -151.8 \\
9Py-CMe & 1.929 & 1.019 & 163.9 & 110.3 & 177.4 & -178.5 & -143.9 \\
\hline
\end{tabular}

The $\mathrm{N}_{1} \mathrm{C}_{2} \mathrm{C}_{3} \mathrm{~N}_{4}, \mathrm{C}_{2} \mathrm{C}_{3} \mathrm{~N}_{4} \mathrm{C}_{5}$, and $\mathrm{N}_{4} \mathrm{C}_{5} \mathrm{C}_{6} \mathrm{~N}_{7}$ dihedral angles indicate the planarity of the polypyrrole before and after its interactions with the $\mathrm{HC}$ gases and therefore could affect its electronic properties. The $\mathrm{C}_{2} \mathrm{C}_{3} \mathrm{~N}_{4} \mathrm{C}_{5}$ dihedral angles remained close to $180^{\circ}$ with only about a $\sim 1^{\circ}$ or less decrease for all complexes, however, both $\mathrm{N}_{1} \mathrm{C}_{2} \mathrm{C}_{3} \mathrm{~N}_{4}$ and $\mathrm{N}_{4} \mathrm{C}_{5} \mathrm{C}_{6} \mathrm{~N}_{7}$ dihedral angles had significant changes for all complexes upon the interaction of polypyrrole with the gases. All complexes exhibited increased planarity for the $\mathrm{N}_{1} \mathrm{C}_{2} \mathrm{C}_{3} \mathrm{~N}_{4}$ dihedral angle, with the most planar observed in 9Py- $\mathrm{CH}\left(177.6^{\circ}\right)$, followed very closely by $9 \mathrm{Py}-\mathrm{CMe}\left(177.4^{\circ}\right), 9 \mathrm{Py}-\mathrm{CCl}\left(161.5^{\circ}\right), 9 \mathrm{Py}-\mathrm{CF}\left(161.3^{\circ}\right)$, and the least planar for 9Py-CS $\left(159.9^{\circ}\right)$ as compared to $9 \mathrm{Py}\left(157.7^{\circ}\right)$. The increase in planarity could be due to the strong electronic effect brought by the interaction of the $\mathrm{HC}$ gases with Py. However, the $\mathrm{N}_{4} \mathrm{C}_{5} \mathrm{C}_{6} \mathrm{~N}_{7}$ dihedral angles were observed to decrease for all complexes, with the lowest observed for 9Py-CMe $\left(-143.9^{\circ}\right)$, followed by $9 \mathrm{Py}-\mathrm{CCl}\left(-146.2^{\circ}\right)$, 9Py-CF $\left(-148.8^{\circ}\right)$, 9Py-CS $\left(-151.8^{\circ}\right)$, and the most planar 9Py-CH $\left(-153.6^{\circ}\right)$ compared to $9 \mathrm{Py}\left(-157.7^{\circ}\right)$. As observed in Figure 2, this dihedral angle is greatly affected by the presence of the bulky $\alpha$-groups $(\mathrm{CMe}$ and $\mathrm{CCl})$ attached to the carbonyl carbon, resulting in an increase in the dihedral angles due to steric effect and the gases with the least bulky $\alpha$-groups (CH and CS) having the smallest increase in dihedral angles. 
9Py

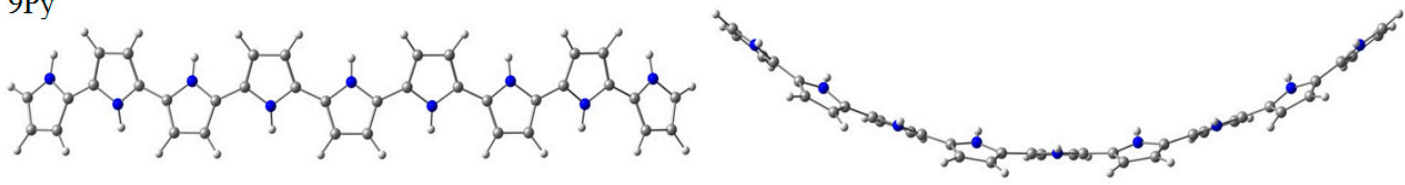

9Py-CCl

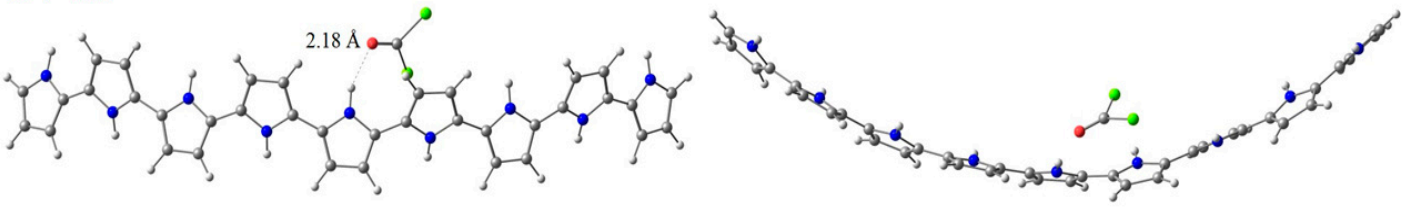

9Py-CF

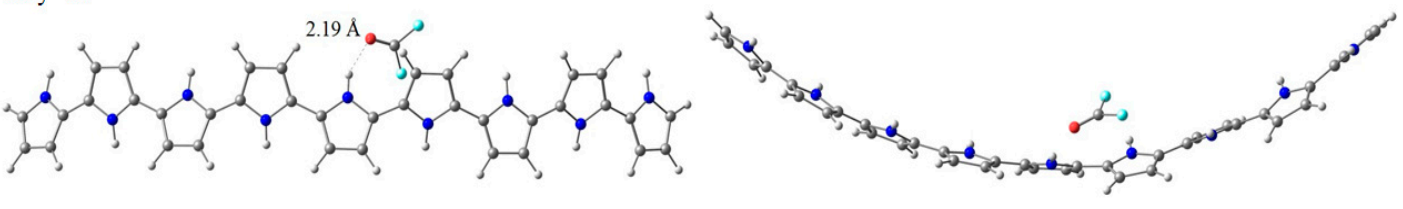

9Py-CH

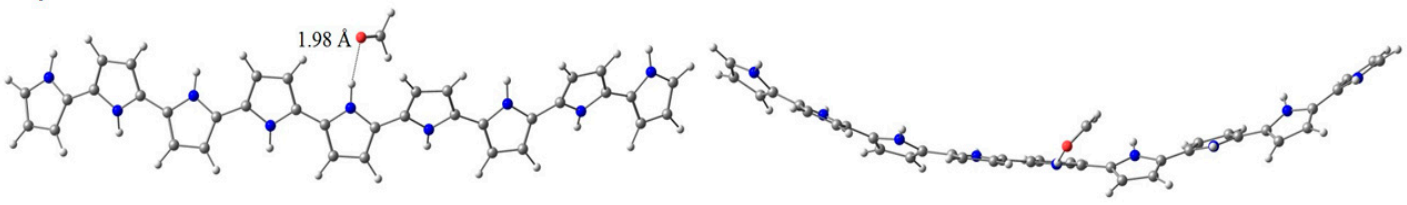

9Py-CS

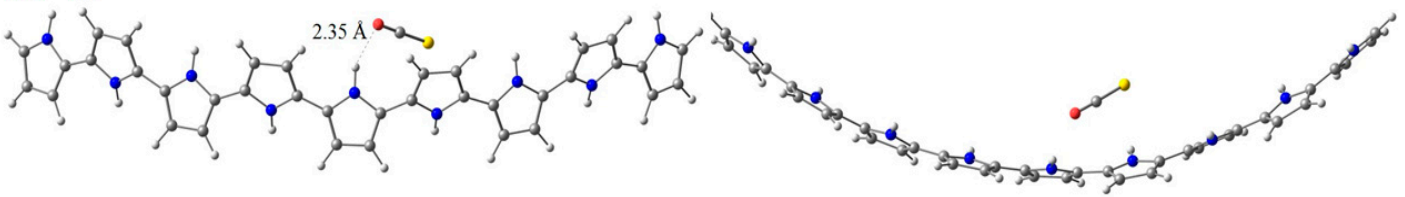

9Py-CMe

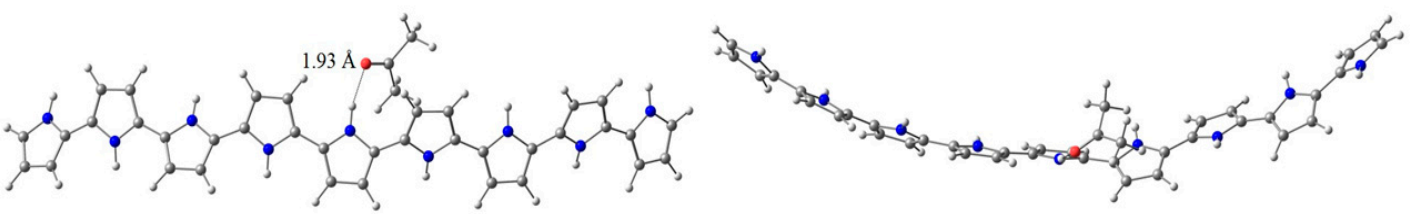

Figure 2. Optimized structures for $9 \mathrm{Py}-\mathrm{HC}$ complexes $(\mathrm{HC}=\mathrm{CCl}, \mathrm{CF}, \mathrm{CH}, \mathrm{CS}$, and $\mathrm{CMe})$ at the B3LYP-D3(BJ)/6-31+G(d) level in the gas phase.

\subsection{Vibrational Analysis of the 9Py-HC Complexes}

The vibrational frequencies of the $9 \mathrm{Py}-\mathrm{HC}$ complexes were observed to decrease from the $3676 \mathrm{~cm}^{-1}\left(\mathrm{~N}_{4}-\mathrm{H}_{8}\right.$ stretching) for the isolated polypyrrole (9Py) upon its interaction with the HC gases. The most significant shift was observed for 9Py-CMe $\left(3482 \mathrm{~cm}^{-1}\right)$, followed by 9Py-CH $\left(3519 \mathrm{~cm}^{-1}\right)$, 9Py-CCl $\left(3636 \mathrm{~cm}^{-1}\right), 9 \mathrm{Py}-\mathrm{CF}\left(3637 \mathrm{~cm}^{-1}\right)$, and CS $\left(3658 \mathrm{~cm}^{-1}\right)$. The observed decrease is due to the weakening of the $\mathrm{N}_{4}-\mathrm{H}_{8}$ bond length, as shown in Table 3, brought by the increase in H-bonding between 9Py and HC gases and has the same trend as the H-bond distances and angles. Thus, the stronger is the H-bond strength, the larger the shift in the vibrational frequencies.

\subsection{Py-HC Complexation Energies}

Table 4 shows the complexation energies for the interaction of 9Py with HC gases for both B3LYP-D3(BJ) and the counterpoise corrected B3LYP-D3(BJ)-CP. The complexation energies show that the BSSE energies are quite significant, about $7-15 \%$ of the corrected complexation energies. The trend observed for the complexation energies is consistent with the structural analysis of the H-bond lengths and 
angles, and vibrational frequencies. The strongest interaction was observed for 9Py-CMe $(-11.64 \mathrm{kcal} / \mathrm{mol})$, followed by 9Py-CH $(-7.98 \mathrm{kcal} / \mathrm{mol})$, 9Py-CCl $(-7.27 \mathrm{kcal} / \mathrm{mol}), 9 \mathrm{Py}-\mathrm{CF}(-6.26 \mathrm{kcal} / \mathrm{mol})$, and the weakest interaction was observed in 9Py-CS $(-5.70 \mathrm{kcal} / \mathrm{mol})$. The complexation energies showed various strengths of interaction, as the $\alpha$-group of the heterocarbonyl gas was varied.

Table 4. Complexation energies for $9 \mathrm{Py}-\mathrm{HC}$ complexes $(\mathrm{HC}=\mathrm{CCl}, \mathrm{CF}, \mathrm{CH}, \mathrm{CS}$, and $\mathrm{CMe})$ at the B3LYP-D3(BJ)-CP/6-31+G(d,p) level in the gas phase.

\begin{tabular}{cccc}
\hline & B3LYP-D3(BJ) & B3LYP-D3(BJ)-CP & BSSE Energy \\
\hline 9Py-HC & $(\mathrm{kcal} / \mathrm{mol})$ & $(\mathrm{kcal} / \mathrm{mol})$ & $(\mathrm{kcal} / \mathrm{mol})$ \\
\hline 9Py-CCl & -8.37 & -7.27 & 1.10 \\
9Py-CF & -7.14 & -6.26 & 0.88 \\
9Py-CH & -8.55 & -7.98 & 0.57 \\
9Py-CS & -6.51 & -5.70 & 0.81 \\
9Py-CMe & -12.46 & -11.64 & 0.82 \\
\hline
\end{tabular}

\subsection{Charge Transfer Analysis}

Table 5 summarizes the NBO population for the HC gases in complex with 9Py. It shows that the various gases have different effects on the polypyrrole, where $\mathrm{CMe}, \mathrm{CH}$, and $\mathrm{CCl}$ gases were observed to donate electron charges to the 9Py (n-doping), while CF and CS gases were observed to accept electron charges from the 9Py ( $p$-doping). The CMe $\left(0.02016 \mathrm{e}^{-}\right)$gas has the highest electron donation, followed by $\mathrm{CH}\left(0.01875 \mathrm{e}^{-}\right)$, and $\mathrm{CCl}\left(0.00292 \mathrm{e}^{-}\right)$, while the CS $\left(-0.00439 \mathrm{e}^{-}\right)$has the strongest electron-accepting capability, followed by CF $\left(-0.00087 \mathrm{e}^{-}\right)$. The high electron-donating capability of $\mathrm{CMe}$ is due to the electron-donating capability of its alkyl methyl groups to the carbonyl O, resulting in electron donation to the polypyrrole and strong $\mathrm{H}$-bond formation. It can be observed that the electron-donating/accepting capability trend of the HC gas has the same trend as the interaction energies and H-bond distances. This is due to the strong electron-withdrawing nature of polypyrrole, having an extensive conjugation and electron delocalization in its backbone. Thus, the stronger the $\mathrm{H}$-bond, i.e., shorter $\mathrm{H}$-bond distance and linear $\mathrm{H}$-bond angle, the easier it is for the polypyrrole to accept electron charge from the HC gases. The effect of the electron charge transfer between 9Py and $\mathrm{HC}$ gases to the frontier orbital energies is then described in the next section.

Table 5. NBO charge transfer analysis for the heterocarbonyl (HC) gases in the 9Py-HC complexes.

\begin{tabular}{cc}
\hline 9Py-HC & $Q_{\text {NBO }}\left(\mathbf{e}^{-}\right)$ \\
\hline 9Py-CCl & 0.00292 \\
9Py-CF & -0.00087 \\
9Py-CH & 0.01875 \\
9Py-CS & -0.00439 \\
9Py-CMe & 0.02016 \\
\hline
\end{tabular}

\subsection{Effect of Carbonyl Gases on the Electronic Properties of Pyrrole}

The changes in the electronic properties of the polypyrrole due to its interaction with heterocarbonyl gases may result in variation in its chemiresistive properties. Since the conductivity of polypyrrole is directly related to its energy gap $\left(E_{G a p}\right)$, understanding the interaction of the HC gases with its frontier orbitals is very important. As shown in Figure 3, there are significant variations in the $E_{\mathrm{HOMO}}$ and $E_{\mathrm{LUMO}}$ energies among different $\mathrm{HC}$ gases. The $E_{\mathrm{HOMO}}$ and the $E_{\mathrm{LUMO}}$ for $9 \mathrm{Py}$ were observed to be at -4.346 and $-1.077 \mathrm{eV}$, respectively, while the $E_{\mathrm{Gap}}$ was determined to be $3.269 \mathrm{eV}$, which is consistent with the experimental $E_{\mathrm{Gap}}$ of $3.1 \mathrm{eV}$ for polypyrrole [84]. The 9Py-CMe complex $(-4.257 \mathrm{eV})$ was observed to have the highest $E_{\mathrm{HOMO}}$ energy increase, followed by $9 \mathrm{Py}-\mathrm{CH}(-4.273 \mathrm{eV})$. On the other hand, the 9Py-CCl $(-4.347 \mathrm{eV})$ has a similar value to polypyrrole, while 9Py-CS $(-4.358 \mathrm{eV})$, $9 \mathrm{Py}-\mathrm{CF}(-4.362 \mathrm{eV})$ have lower $E_{\mathrm{HOMO}}$ energies. The observed changes could be attributed to, as 
discussed in the previous section, the electron donation of the $\mathrm{CMe}$ and $\mathrm{CH}$ gases to the $E_{\mathrm{HOMO}}$ of 9Py. As will be discussed in the next section, the HOMO surfaces of the complexes mainly have the 9Py character, therefore, electron donation to the 9Py backbone will result in an increase in the $E_{\mathrm{HOMO}}$ energy. The opposite happens when the 9Py instead donates an electron charge to the HC gases, where the $E_{\mathrm{HOMO}}$ orbitals are either unchanged or result in lower energy. For the $E_{\mathrm{LUMO}}$ energies, the values are similar to the $E_{\mathrm{LUMO}}$ energies of the isolated $\mathrm{HC}$ gases and, as can be seen in Figure 5 in the next section, the LUMO surfaces mainly have the HC gas LUMO character. The $E_{\mathrm{LUMO}}$ energies of the $9 \mathrm{Py}-\mathrm{HC}$ complexes and the $E_{\mathrm{LUMO}}$ energies of the isolated gases $\left(E_{\mathrm{LUMO}}\right.$, complex $/ E_{\mathrm{LUMO}} \mathrm{HC}$ gas $)$ are: 9Py-CCl $(-2.203 \mathrm{eV} /-2.085 \mathrm{eV}), 9 \mathrm{Py}-\mathrm{CF}(-1.235 \mathrm{eV} /-1.162 \mathrm{eV}), 9 \mathrm{Py}-\mathrm{CH}(-2.102 \mathrm{eV} /-1.7039 \mathrm{eV})$, 9Py-CS $(-1.249 \mathrm{eV} /-1.216 \mathrm{eV})$, and 9Py-CMe $(-1.177 \mathrm{eV} /-0.740 \mathrm{eV})$. All the $E_{\text {LuMO }}$ energies were observed to decrease as 9Py interacts with the HC gases and result in smaller $E_{\mathrm{Gap}}$ values for all the 9Py-HC complexes compared to isolated 9Py. Due to the interaction of the different $\mathrm{HC}$ gases and its interaction with the frontier orbital energies of 9Py, varying $E_{\mathrm{Gap}}$ values were observed for the 9Py-HC complexes. The smallest $E_{\text {Gap }}$ was observed for 9Py-CCl $(2.144 \mathrm{eV})$, followed by 9Py-CH $(2.171 \mathrm{eV})$, 9Py-CMe (3.081 eV), 9Py-CS (3.109 eV), and the largest was observed for 9Py-CF (3.128 eV). Table 6 presents a summary of the frontier orbital energies $\left(E_{\mathrm{HOMO}}\right.$ and $\left.E_{\mathrm{LUMO}}\right), E_{\mathrm{Gap}}$, ionization potential $(I P)$, and electron affinity $(E A)$, where the IP and EA were estimated using Koopman's theorem: $\mathrm{IP}=-E_{\mathrm{HOMO}}$ and $\mathrm{EA}=-E_{\mathrm{LUMO}}$. The analysis of the calculated electronic energies demonstrates the potential sensitivity (significant reduction in $E_{\mathrm{Gap}}$ values), especially for $\mathrm{CCl}$ and $\mathrm{CH}$ and the selectivity (variation in $E_{\text {Gap }}$ values for different $\mathrm{HC}$ gases) of polypyrrole as a potential sensor of the heterocarbonyl gases in this study. In order to further understand the effect of concentration, interferents, and charge transport along the polymer due to the interaction of the gas molecules with polypyrrole, large-scale molecular dynamics or monte carlo simulations are recommended [85-88].

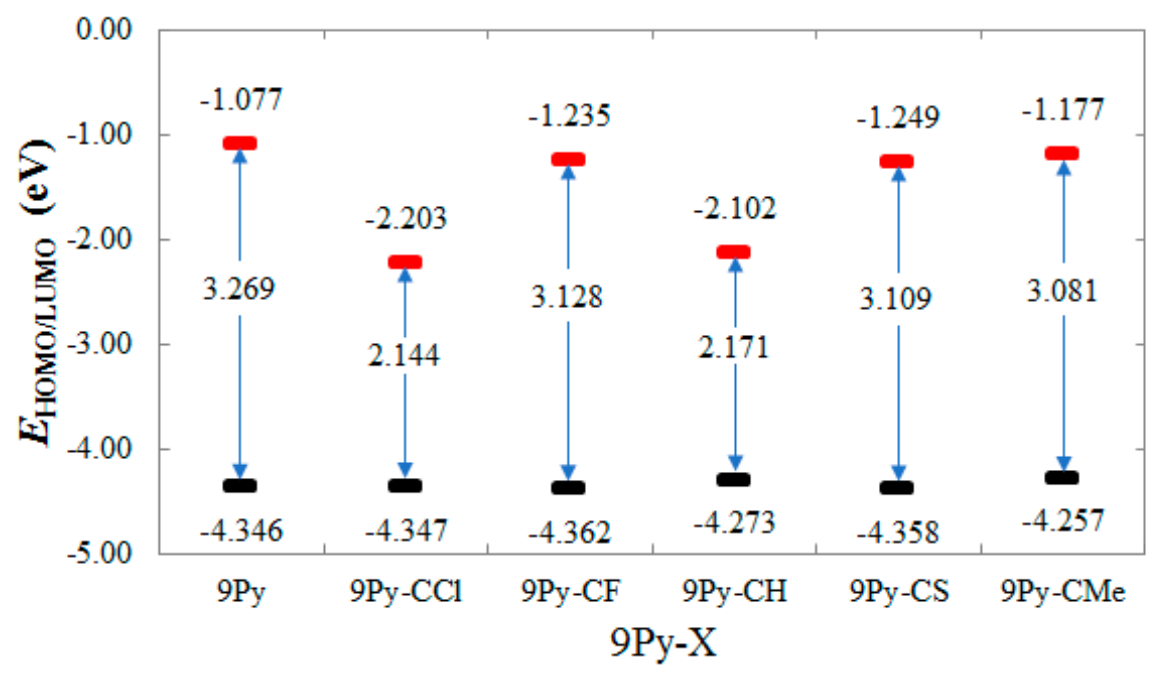

Figure 3. Frontier orbital energies: $E_{\mathrm{HOMO}}$ (black marker), $E_{\mathrm{LUMO}}$ (red marker), and $E_{\mathrm{Gap}}$ (arrow) for the $9 \mathrm{Py}-\mathrm{HC}$ complexes $(\mathrm{HC}=\mathrm{CCl}, \mathrm{CF}, \mathrm{CH}, \mathrm{CS}$, and $\mathrm{CMe})$.

Table 6. Frontier orbital energies $\left(E_{\mathrm{HOMO}}, E_{\mathrm{LUMO}}, E_{\mathrm{Gap}}\right)$, ionization potential, and electron affinity for the 9Py-HC complexes.

\begin{tabular}{cccccc}
\hline 9Py-HC & $\boldsymbol{E}_{\text {HOMO }}(\mathbf{e V})$ & $\boldsymbol{E}_{\text {LUMO }}(\mathbf{e V})$ & $\boldsymbol{E}_{\text {Gap }}(\mathbf{e V})$ & IP (eV) & EA (eV) \\
\hline 9Py & -4.346 & -1.077 & 3.269 & 4.346 & 1.077 \\
9Py-CCl & -4.347 & -2.203 & 2.144 & 4.347 & 2.203 \\
9Py-CF & -4.362 & -1.235 & 3.128 & 4.362 & 1.235 \\
9Py-CH & -4.273 & -2.102 & 2.171 & 4.273 & 2.102 \\
9Py-CS & -4.358 & -1.249 & 3.109 & 4.358 & 1.249 \\
9Py-CMe & -4.346 & -1.077 & 3.269 & 4.346 & 1.077 \\
\hline
\end{tabular}




\subsection{Density of States}

To have a better understanding of the electronic properties of the 9Py-HC complexes, the density of states (DOS) and the frontier molecular orbital (FMO) surfaces are discussed. Figure 4 shows the total density of states (TDOS) of the 9Py-HC complexes and the isolated 9Py, and the projected density of states (PDOS) of the HC gases, while Figure 5 shows the HOMO and LUMO surfaces of the isolated 9Py and 9Py-HC complexes. The TDOS curves in Figure 5 show additional peaks or increased density in the LUMO energy region, mainly due to the LUMO orbitals of the HC gases, and are shown as large orbital densities in the LUMO surfaces in Figure 6. The 9Py-CCl and $9 \mathrm{Py}-\mathrm{CH}$ were both observed to have the smallest $E_{\text {Gap }}$ values due to the existence of the additional peak in the TDOS of the two complexes, significantly reducing their LUMO energies, resulting in much lower $E_{\text {Gap }}$ values. For 9Py-CMe, 9Py-CF, and 9Py-CS, the reduction in LUMO energies is minimal since the LUMO energies of these HC gases are only slightly lower than the LUMO energy of the isolated 9Py, resulting in less lowering in the $E_{\mathrm{Gap}}$ values. For the $\mathrm{HOMO}$ energies, the $9 \mathrm{Py}-\mathrm{CMe}$ and $9 \mathrm{Py}-\mathrm{CH}$ complexes have higher HOMO energies as compared to the rest of the complexes and result in more effective electron transfer to the 9Py, thus significantly increasing their HOMO energies. The combination of the HOMO and LUMO orbital interactions of the HC gases resulted in varying electronic properties of the 9Py-HC complexes.
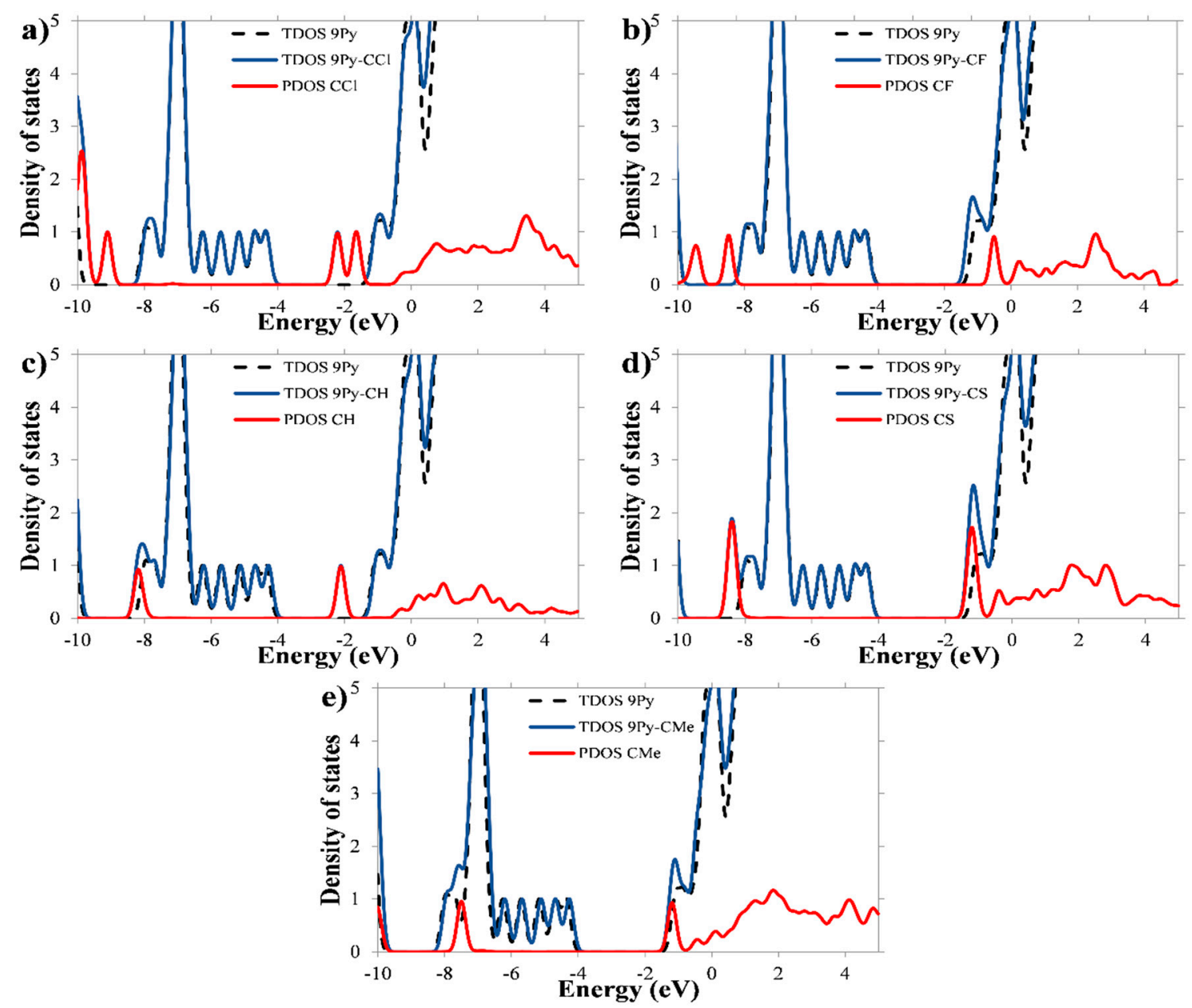

Figure 4. The total density of states (TDOS) for 9Py-HC complexes (solid blue line), projected density of states (PDOS) for the HC gases (red line), and TDOS for the isolated 9Py (dashed black line): (a) 9Py-CCl, (b) 9Py-CF, (c) 9Py-CH, (d) 9Py-CS, and (e) 9Py-CMe. 
HOMO

9Py

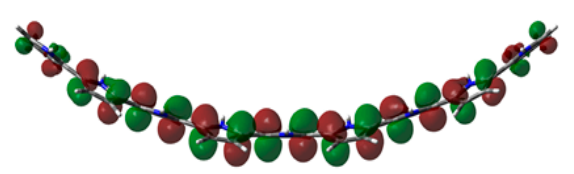

9Py-CCl

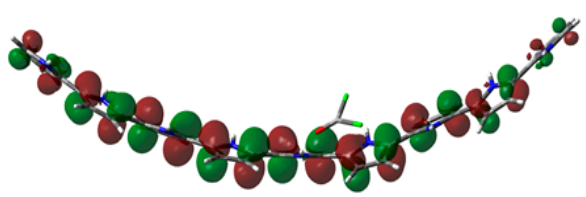

9Py-CF

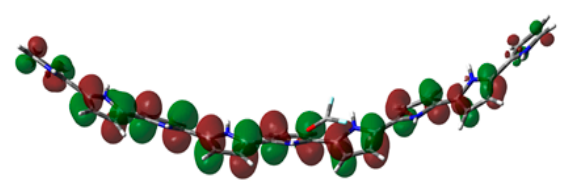

9Py-CH

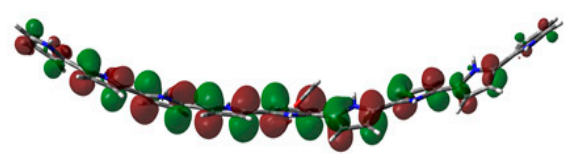

9Py-CS

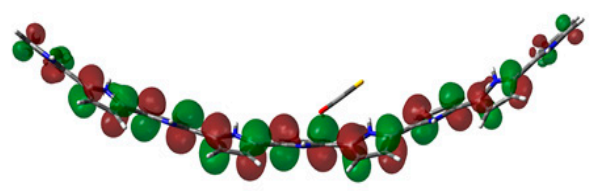

9Py-CMe

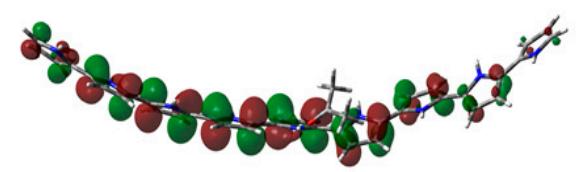

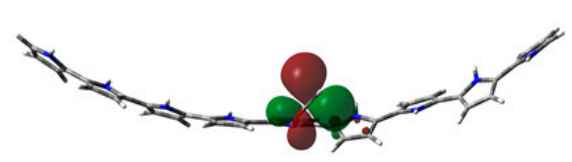

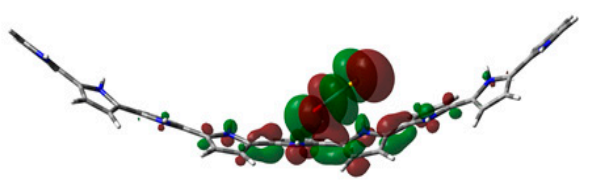

LUMO
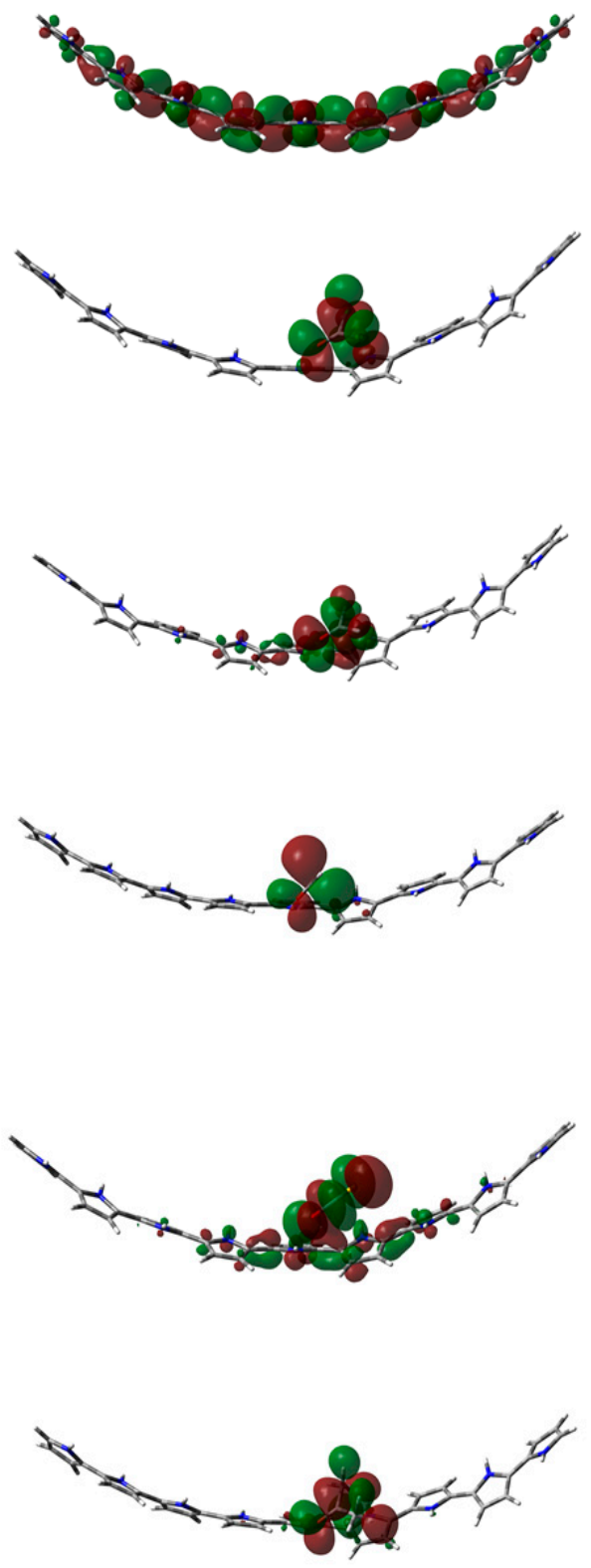

Figure 5. Frontier molecular orbital surface for the 9Py-HC complexes (isovalue $=0.02$ a.u.).

\subsection{Simulated UV-Vis Absorption Spectra of the 9Py-HC Complexes}

Figure 6 shows the simulated UV-Vis absorption spectra of the 9Py-HC gases. The changes in the electronic structure of the 9Py results in changes in its chemiresistivity and also in its optical properties. As described in the previous sections, the $E_{\mathrm{Gap}}$ values decreased upon the interaction of $\mathrm{HC}$ gases with 9Py. The same was also observed in the excitation spectra of the 9Py-HC complexes. The isolated 9Py showed three major peaks at $436\left(\lambda_{\max }\right), 372$, and $345 \mathrm{~nm}$ (shoulder) consistent with previous reports $[52,55,89,90]$. The $\lambda_{\max }$ at $436 \mathrm{~nm}(2.85 \mathrm{eV})$, attributed to the $\pi \longrightarrow \pi^{*}$ excitation, is consistent with the previous experimental value of $442 \mathrm{~nm}$ for polypyrrole [89-91]. The $\lambda_{\max }$ ( $E_{\text {excited, } \max }$ ) of the $9 \mathrm{Py}-\mathrm{HC}$ complexes, as shown in Table 7 , are similar to the $\lambda_{\max }$ of 9Py with a slight red-shift for 9Py-CH $(439 \mathrm{~nm} / 2.82 \mathrm{eV})$ and 9Py-CMe $(438 \mathrm{~nm} / 2.83 \mathrm{eV})$, while a slight blue-shift was observed for 9Py-CCl $(431 \mathrm{~nm} / 2.88 \mathrm{eV}), 9 \mathrm{Py}-\mathrm{CF}(432 \mathrm{~nm} / 2.87 \mathrm{eV})$, and 9Py-CS $(431 \mathrm{~nm} / 2.88 \mathrm{eV})$. On the other hand, 
the first singlet excitations ( $E_{\text {excited, } 1 \text { st }}$ ), although at significantly lower oscillator strengths, for all 9Py-HC complexes have significantly shifted to longer wavelengths with the $9 \mathrm{Py}-\mathrm{CCl}(743 \mathrm{~nm} / 1.67 \mathrm{eV})$ and $9 \mathrm{Py}-\mathrm{CH}(737 \mathrm{~nm} / 1.68 \mathrm{eV})$ having the longest red-shifts, followed by 9Py-CMe $(476 \mathrm{~nm} / 2.60 \mathrm{eV})$, 9Py-CS $(472 \mathrm{~nm} / 2.62 \mathrm{eV})$, and 9Py-CF $(469 \mathrm{~nm} / 2.65 \mathrm{eV})$. The $E_{\text {excited, } 1 \text { st }}$ are assigned to the $\pi\left(\mathrm{HOMO}_{\mathrm{Py}}\right)$ $\longrightarrow \pi^{*}\left(\mathrm{LUMO}_{\mathrm{HC}}\right)$ transitions from the HOMO (bonding $\pi$-orbital) of 9Py to the LUMO (antibonding $\pi$-orbital) of the HC gases, as described in the previous section, while the $E_{\text {excited, max }}$ are assigned to the $\pi\left(\mathrm{HOMO}_{\mathrm{Py}}\right) \longrightarrow \pi^{*}\left(\mathrm{LUMO}_{\mathrm{Py}}\right)$ transitions from the HOMO of 9Py to the LUMO of 9Py. The observed large red shifts in the complexes, especially for $\mathrm{CCl}$ and $\mathrm{CH}$, demonstrate the potential sensitivity of polypyrrole via UV-Vis absorbance measurements.

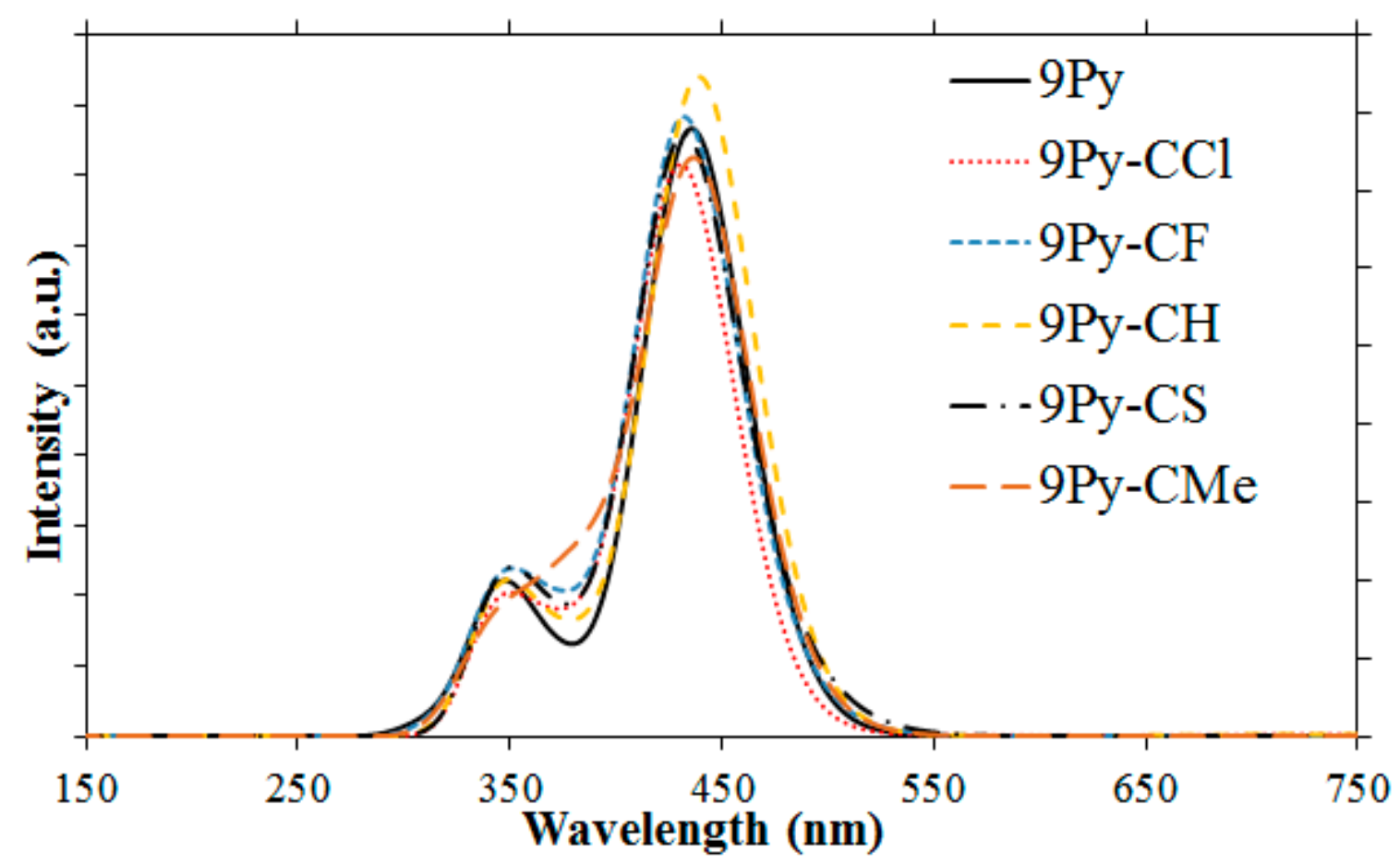

Figure 6. Simulated UV-Vis absorption spectra for 9Py and the 9Py-HC complexes (FWHM = $\left.3000 \mathrm{~cm}^{-1}\right)$.

Table 7. Excitation energies for the maximum absorbance $\left(E_{\text {excited, max }}\right)$ and first excited state $\left(E_{\text {excited, 1st }}\right)$, oscillator strengths $\left(f_{\mathrm{Osc}}\right)$ of $9 \mathrm{Py}-\mathrm{HC}$. The corresponding main electronic configurations $(>5 \%)$ are also shown.

\begin{tabular}{ccccc}
\hline 9Py-HC & $\boldsymbol{E}_{\text {excited, } \mathbf{m a x}}, \mathbf{e V}\left(\boldsymbol{\lambda}_{\text {max }}, \mathbf{n m}\right)$ & $\boldsymbol{f}_{\text {Osc }}$ & $\boldsymbol{E}_{\text {excited }}, \mathbf{1 s t}, \mathbf{e V}\left(\boldsymbol{\lambda}_{\mathbf{1 s t}}, \mathbf{n m}\right)$ & $\boldsymbol{f}_{\text {Osc }}$ \\
\hline 9Py & $2.85(436) \mathrm{H} \longrightarrow \mathrm{L}(95 \%)$ & 2.3834 & -- & \\
9Py-CCl & $2.88(431) \mathrm{H} \longrightarrow \mathrm{L}+2(93 \%)$ & 2.2274 & $1.67(743) \mathrm{H} \longrightarrow \mathrm{L}(95 \%)$ & 0.0065 \\
9Py-CF & $2.87(432) \mathrm{H} \longrightarrow \mathrm{L}+1(93 \%)$ & 2.1357 & $2.65(469) \mathrm{H} \longrightarrow \mathrm{L}(94 \%)$ & 0.1148 \\
9Py-CH & $2.82(439) \mathrm{H} \longrightarrow \mathrm{L}+1(93 \%)$ & 2.3113 & $1.68(737) \mathrm{H} \longrightarrow \mathrm{L}(97 \%)$ & 0.0057 \\
9Py-CS & $2.88(431) \mathrm{H} \longrightarrow \mathrm{L}+2(92 \%)$ & 2.0309 & $2.62(472) \mathrm{H} \longrightarrow \mathrm{L}(93 \%)$ & 0.1818 \\
9Py-CMe & $2.83(438) \mathrm{H} \longrightarrow \mathrm{L}+1(90 \%)$ & 1.9847 & $2.60(476) \mathrm{H} \longrightarrow \mathrm{L}(96 \%)$ & 0.0304 \\
\hline
\end{tabular}

\section{Conclusions}

The potential of polypyrrole as a gas sensor for several toxic heterocarbonyl gases: phosgene, carbonyl fluoride, formaldehyde, carbonyl sulfide, and acetone was successfully described by DFT calculations. The B3LYP-D3/6-31+G(d,p) level for geometry optimizations and the B3LYP-D3-CP/6-31+G(d,p) level for energy calculations were found to be sufficient in describing non-covalent interactions when tested against several high-level DFT methods employing the Dunning's aug-cc-pVDZ and aug-ccpVTZ basis sets. The resulting geometries of the complexes from the interaction 
of the heterocarbonyl gases with polypyrrole were observed to have significant effects on its structural parameters. Increased planarity was observed in the non-interacting region of the polymer due to electronic effects, while decreased planarity was observed in the interacting region due to steric effects. The analysis of the H-bond distances, vibrational frequencies, and complexation energies show that among the heterocarbonyl gases, acetone $(\mathrm{CMe})$ had the strongest interaction as a result of the electron charge transfer ( $n$-doping) of the acetone molecule to the polypyrrole backbone. The acetone and formaldehyde $(\mathrm{CH})$ gases were observed to have significant electron charge donation to the polypyrrole backbone which increases the HOMO energies of these two complexes. On the other hand, the carbonyl fluoride (CF) and carbonyl sulfide (CS) gases were observed to receive electron charges from the polypyrrole backbone, resulting in a decrease in their HOMO energies. The LUMO orbitals of the complexes were observed to mainly have the LUMO orbital character of the heterocarbonyl gases. Due to the significantly lower LUMO energies of phosgene and formaldehyde gases, the LUMO energies of their complexes were observed to have the lowest energies, resulting in the smallest energy gaps among the gases studied. This demonstrates the potential chemiresistive sensitivities to these two gases. The first excited singlet states from the absorption calculations have the same trend as the energy gap values and were shown to be due to the $\pi\left(\mathrm{HOMO}_{\mathrm{Py}}\right) \longrightarrow \pi^{*}\left(\mathrm{LUMO}_{\mathrm{HC}}\right)$ energy transition from the HOMO orbital of polypyrrole to the LUMO orbital of the gas. The significant changes and variation among different analyte gases in their electronic and optical properties reveal its potential sensitivity and selectivity. The analysis and results in this study demonstrate the promise of polypyrrole as a sensor for various toxic heterocarbonyl gases and may aid in its future experiments and design.

Supplementary Materials: The following are available online at http://www.mdpi.com/2227-9040/8/3/84/s1, Table S1: Cartesian coordinates, lowest vibrational frequencies, and total energies of 9Py and the 9Py-HC complexes.

Funding: This research received no external funding.

Acknowledgments: F.F.J. would like to thank the Philippine Council for Industry, Energy, and Emerging Technology Research and Development of the Department of Science and Technology, Philippines (DOST-PCIEERD) and the University Research Coordination Office of De La Salle University (DLSU-URCO) for the support and computational resources.

Conflicts of Interest: The authors declare no conflict of interest.

\section{References}

1. Holmes, W.W.; Keyser, B.M.; Paradiso, D.C.; Ray, R.; Andres, D.K.; Benton, B.J.; Rothwell, C.C.; Hoard-Fruchey, H.M.; Dillman, J.F.; Sciuto, A.M.; et al. Conceptual approaches for treatment of phosgene inhalation-induced lung injury. Toxicol. Lett. 2016, 244, 8-20. [CrossRef] [PubMed]

2. Januszkiewicz, A.J.; Bazar, M.A.; Crouse, L.C.B.; Chapman, M.A.; Hodges, S.E.; McCormick, S.J.; O’Neill, A.J. Morbidity and mortality resulting from acute inhalation exposures to hydrogen fluoride and carbonyl fluoride in rats. Inhal. Toxicol. 2018, 30, 114-123. [CrossRef] [PubMed]

3. D’Henry, A.H.; Casanova, M.; Starr, T.B. Formaldehyde Toxicity-New Understanding. Crit. Rev. Toxicol. 1990, 20, 397-426. [CrossRef]

4. Xie, H.; Wu, Y.; Zeng, F.; Chen, J.; Wu, S. An AIE-based fluorescent test strip for the portable detection of gaseous phosgene. Chem. Commun. 2017, 53, 9813-9816. [CrossRef] [PubMed]

5. Fawcett, F.S.; Tullock, C.W.; Coffman, D.D. The Chemistry of Carbonyl Fluoride. I. The Fluorination of Organic Compounds. J. Am. Chem. Soc. 1962, 84, 4275-4285. [CrossRef]

6. Burkhart, K.K.; Britt, A.; Petrini, G.; O’Donnell, S.; Ward, J. Pulmonary Toxicity Following Exposure to an Aerosolized Leather Protector. J. Toxicol. Clin. Toxicol. 1996, 34, 21-24. [CrossRef]

7. Luecken, D.J.; Hutzell, W.T.; Strum, M.L.; Pouliot, G.A. Regional sources of atmospheric formaldehyde and acetaldehyde, and implications for atmospheric modeling. Atmos. Environ. 2012, 47, 477-490. [CrossRef]

8. Soffritti, M.; Maltoni, C.; Maffei, F.; Biagi, R. Formaldehyde: An Experimental Multipotential Carcinogen. Toxicol. Ind. Health 1989, 5, 699-730. [CrossRef]

9. Watts, S.F. The mass budgets of carbonyl sulfide, dimethyl sulfide, carbon disulfide and hydrogen sulfide. Atmos. Environ. 2000, 34, 761-779. [CrossRef] 
10. Bartholomaeus, A.R.; Haritos, V.S. Review of the toxicology of carbonyl sulfide, a new grain fumigant. Food Chem. Toxicol. 2005, 43, 1687-1701. [CrossRef]

11. Bruckner, J.V.; Peterson, R.G. Evaluation of toluene and acetone inhalant abuse. Toxicol. Appl. Pharmacol. 1981, 61, 27-38. [CrossRef]

12. Jacob, D.J.; Field, B.D.; Jin, E.M.; Bey, I.; Li, Q.; Logan, J.A.; Yantosca, R.M.; Singh, H.B. Atmospheric budget of acetone. J. Geophys. Res. Atmos. 2002, 107, ACH-5. [CrossRef]

13. Gao, C.; Govind, R.; Tabak, H.H. Application of the group contribution method for predicting the toxicity of organic chemicals. Environ. Toxicol. Chem. 1992, 11, 631-636. [CrossRef]

14. Dunlap, K.L. Phosgene. In Kirk-Othmer Encyclopedia of Chemical Technology; John Wiley \& Sons, Inc.: Hoboken, NJ, USA, 2010.

15. Considine, G.D.; Kulik, P.H. (Eds.) Carbonyl Sulfide. In Van Nostrand's Scientific Encyclopedia; John Wiley \& Sons, Inc.: Hoboken, NJ, USA, 2007.

16. Ryan, T.A.; Ryan, C.; Seddon, E.A.; Seddon, K.R. (Eds.) Carbonyl Difluoride. In Topics in Inorganic and General Chemistry; Elsevier: Amsterdam, The Netherlands, 1996; pp. 545-664.

17. Huang, X.H.H.; Ip, H.S.S.; Yu, J.Z. Determination of trace amounts of formaldehyde in acetone. Anal. Chim. Acta 2007, 604, 134-138. [CrossRef]

18. Balz, E.H. Acetone-Formaldehyde Resins. U.S. Patent 2,237,325, 8 April 1941.

19. Shukla, S.K.; Kushwaha, C.S.; Singh, N.B. Recent developments in conducting polymer based composites for sensing devices. Mater. Today Proc. 2017, 4, 5672-5681. [CrossRef]

20. Park, S.; Park, C.; Yoon, H. Chemo-Electrical Gas Sensors Based on Conducting Polymer Hybrids. Polymers 2017, 9, 155. [CrossRef]

21. Grate, J.W. Acoustic Wave Microsensor Arrays for Vapor Sensing. Chem. Rev. 2000, 100, 2627-2648. [CrossRef]

22. Natori, K. Ballistic metal-oxide-semiconductor field effect transistor. J. Appl. Phys. 1994, 76, 4879-4890. [CrossRef]

23. Yoon, H. Current Trends in Sensors Based on Conducting Polymer Nanomaterials. Nanomaterials 2013, 3, 524-549. [CrossRef]

24. Gusain, A.; Joshi, N.J.; Varde, P.V.; Aswal, D.K. Flexible NO gas sensor based on conducting polymer poly [ N -9'-heptadecanyl-2,7-carbazole-alt-5,5-(4', $7^{\prime}$-di-2-thienyl-2' ${ }^{\prime} 1^{\prime}, 3^{\prime}$-benzothiadiazole)] (PCDTBT). Sens. Actuators B Chem. 2017, 239, 734-745. [CrossRef]

25. Franco, F.C., Jr.; Padama, A.A.B. DFT and TD-DFT study on the structural and optoelectronic characteristics of chemically modified donor-acceptor conjugated oligomers for organic polymer solar cells. Polymer 2016, 97, 55-62. [CrossRef]

26. Franco, F.C.; Padama, A.A.B. On the Structural and Optoelectronic Properties of Chemically Modified Oligothiophenes with Electron-Withdrawing Substituents for Organic Solar Cell Applications: A DFT/TDDFT Study. J. Phys. Soc. Jpn. 2017, 86, 064802. [CrossRef]

27. Kreuer, K.D. On the development of proton conducting polymer membranes for hydrogen and methanol fuel cells. J. Membr. Sci. 2001, 185, 29-39. [CrossRef]

28. Park, K.-S.; Schougaard, S.B.; Goodenough, J.B. Conducting-Polymer/Iron-Redox-Couple Composite Cathodes for Lithium Secondary Batteries. Adv. Mater. 2007, 19, 848-851. [CrossRef]

29. Mulzer, C.R.; Shen, L.; Bisbey, R.P.; McKone, J.R.; Zhang, N.; Abruña, H.D.; Dichtel, W.R. Superior Charge Storage and Power Density of a Conducting Polymer-Modified Covalent Organic Framework. ACS Cent. Sci. 2016, 2, 667-673. [CrossRef] [PubMed]

30. Xuan, Y.; Sandberg, M.; Berggren, M.; Crispin, X. An all-polymer-air PEDOT battery. Org. Electron. 2012, 13, 632-637. [CrossRef]

31. Zhou, E.; Hashimoto, K.; Tajima, K. Low band gap polymers for photovoltaic device with photocurrent response wavelengths over $1000 \mathrm{~nm}$. Polymer 2013, 54, 6501-6509. [CrossRef]

32. Sung, J.-H.; Kim, S.-J.; Lee, K.-H. Fabrication of microcapacitors using conducting polymer microelectrodes. J. Power Source 2003, 124, 343-350. [CrossRef]

33. Al-Mashat, L.; Debiemme-Chouvy, C.; Borensztajn, S.; Wlodarski, W. Electropolymerized Polypyrrole Nanowires for Hydrogen Gas Sensing. J. Phys. Chem. C 2012, 116, 13388-13394. [CrossRef]

34. Srivastava, S.; Sharma, S.S.; Agrawal, S.; Kumar, S.; Singh, M.; Vijay, Y.K. Study of chemiresistor type CNT doped polyaniline gas sensor. Synth. Met. 2010, 160, 529-534. [CrossRef] 
35. Li, Y.; Yang, M. Bilayer thin film humidity sensors based on sodium polystyrenesulfonate and substituted polyacetylenes. Sens. Actuators B Chem. 2002, 87, 184-189. [CrossRef]

36. Liao, F.; Yin, S.; Toney, M.F.; Subramanian, V. Physical discrimination of amine vapor mixtures using polythiophene gas sensor arrays. Sens. Actuators B Chem. 2010, 150, 254-263. [CrossRef]

37. Galar, P.; Dzurnak, B.; Maly, P.; Cermak, J.; Kromka, A.; Omastova, M.; Rezek, B. Chemical Changes and Photoluminescence Properties of UV Modified Polypyrrole. Int. J. Electrochem. Sci. 2013, 8, 57-70.

38. Paul, S.; Chavan, N.N.; Radhakrishnan, S. Polypyrrole functionalized with ferrocenyl derivative as a rapid carbon monoxide sensor. Synth. Met. 2009, 159, 415-418. [CrossRef]

39. Li, G.; Wang, Y.; Xu, H. A Hydrogen Peroxide Sensor Prepared by Electropolymerization of Pyrrole Based on Screen-Printed Carbon Paste Electrodes. Sensors 2007, 7, 239-250. [CrossRef]

40. Joshi, A.; Gangal, S.A.; Gupta, S.K. Ammonia sensing properties of polypyrrole thin films at room temperature. Sens. Actuators B Chem. 2011, 156, 938-942. [CrossRef]

41. Campos, M.; Simões, F.R.; Pereira, E.C. Influence of methane in the electrical properties of polypyrrole films doped with dodecylbenzene sulfonic acid. Sens. Actuators B Chem. 2007, 125, 158-166. [CrossRef]

42. Mahmoudian, M.R.; Alias, Y.; Basirun, W.J.; MengWoi, P.; Jamali-Sheini, F.; Sookhakian, M.; Silakhori, M. A sensitive electrochemical nitrate sensor based on polypyrrole coated palladium nanoclusters. J. Electroanal. Chem. 2015, 751, 30-36. [CrossRef]

43. Babaei, M.; Alizadeh, N. Methanol selective gas sensor based on nano-structured conducting polypyrrole prepared by electrochemically on interdigital electrodes for biodiesel analysis. Sens. Actuators B Chem. 2013, 183, 617-626. [CrossRef]

44. Pirsa, S.; Alizadeh, N. A selective DMSO gas sensor based on nanostructured conducting polypyrrole doped with sulfonate anion. Sens. Actuators B Chem. 2012, 168, 303-309. [CrossRef]

45. Pirsa, S.; Alizadeh, N. Design and fabrication of gas sensor based on nanostructure conductive polypyrrole for determination of volatile organic solvents. Sens. Actuators B Chem. 2010, 147, 461-466. [CrossRef]

46. Do, J.-S.; Wang, S.-H. On the sensitivity of conductimetric acetone gas sensor based on polypyrrole and polyaniline conducting polymers. Sens. Actuators B Chem. 2013, 185, 39-46. [CrossRef]

47. Pirsa, S.; Alizadeh, N. Nanoporous Conducting Polypyrrole Gas Sensor Coupled to a Gas Chromatograph for Determination of Aromatic Hydrocarbons Using Dispersive Liquid-Liquid Microextraction Method. IEEE Sens. J. 2011, 11, 3400-3405. [CrossRef]

48. Kotresh, S.; Ravikiran, Y.T.; Vijaya Kumari, S.C.; Chandrasekhar, T.; Ramana, C.V.V.; Thomas, S. Solution-based Spin Cast Processed Polypyrrole/Niobium Pentoxide Nanocomposite as Room Temperature Liquefied Petroleum Gas Sensor. Mater. Manuf. Process. 2016, 31, 1976-1982. [CrossRef]

49. Bibi, S.; Ullah, H.; Ahmad, S.M.; Ali Shah, A.-H.; Bilal, S.; Tahir, A.A.; Ayub, K. Molecular and Electronic Structure Elucidation of Polypyrrole Gas Sensors. J. Phys. Chem. C 2015, 119, 15994-16003. [CrossRef]

50. Marutaphan, A.; Wongchoosuk, C. SCC-DFTB Study on Structure, Electronic and Sensing Properties of Polypyrrole. J. Phys. Conf. Ser. 2017, 901, 012079. [CrossRef]

51. Saha, J.K.; Hossain, M.S.; Ghosh, M.K. DFT study of response mechanism and selectivity of poly(3,4-ethylenedioxythiophene) towards $\mathrm{CO}_{2}$ and $\mathrm{SO}_{2}$ as gas sensor. Struct. Chem. 2019, 30, 1427-1436. [CrossRef]

52. Ullah, H.; Ayub, K.; Ullah, Z.; Hanif, M.; Nawaz, R.; Shah, A.-H.A.; Bilal, S. Theoretical insight of polypyrrole ammonia gas sensor. Synth. Met. 2013, 172, 14-20. [CrossRef]

53. Rad, A.S.; Nasimi, N.; Jafari, M.; Shabestari, D.S.; Gerami, E. Ab-initio study of interaction of some atmospheric gases $\left(\mathrm{SO}_{2}, \mathrm{NH}_{3}, \mathrm{H}_{2} \mathrm{O}, \mathrm{CO}, \mathrm{CH}_{4}\right.$ and $\left.\mathrm{CO}_{2}\right)$ with polypyrrole (3PPy) gas sensor: DFT calculations. Sens. Actuators B Chem. 2015, 220, 641-651. [CrossRef]

54. Shokuhi Rad, A.; Zardoost, M.R.; Abedini, E. First-principles study of terpyrrole as a potential hydrogen cyanide sensor: DFT calculations. J. Mol. Model. 2015, 21, 273. [CrossRef]

55. Wasim, F.; Mahmood, T.; Ayub, K. An accurate cost effective DFT approach to study the sensing behaviour of polypyrrole towards nitrate ions in gas and aqueous phases. Phys. Chem. Chem. Phys. 2016, 18, 19236-19247. [CrossRef] [PubMed]

56. Franco, F.C. Electronic and Optical Properties of Polypyrrole as a Toxic Carbonyl Gas Sensor. In Theory and Simulation in Physics for Materials Applications; Springer: Cham, Switzerland, 2020; pp. 163-179.

57. Ullah, H.; Tahir, A.A.; Mallick, T.K. Polypyrrole/ $\mathrm{TiO}_{2}$ composites for the application of photocatalysis. Sens. Actuators B Chem. 2017, 241, 1161-1169. [CrossRef] 
58. Ullah, H. Inter-molecular interaction in Polypyrrole/TiO 2 : A DFT study. J. Alloys Compd. 2017, 692, 140-148. [CrossRef]

59. Franco, F., Jr. Computational study on the structural and optoelectronic properties of a carbazole-benzothiadiazole based conjugated oligomer with various alkyl side-chain lengths. Mol. Simul. 2017, 43, 222-227. [CrossRef]

60. Franco, F.C., Jr. Computational Study on Optoelectronic Property Tuning of Oligothiophenes via Chemical Modifications for Solar Cell Applications. Asian J. Chem. 2018, 30, 329-332. [CrossRef]

61. Franco, F.C. Tuning the optoelectronic properties of oligothiophenes for solar cell applications by varying the number of cyano and fluoro substituents for solar cell applications: A theoretical study. J. Chem. Res. 2020, 44, 235-242. [CrossRef]

62. Roncali, J. Molecular Engineering of the Band Gap of $\pi$-Conjugated Systems: Facing Technological Applications. Macromol. Rapid Commun. 2007, 28, 1761-1775. [CrossRef]

63. Jia, X.; Chen, Z.; Duan, C.; Wang, Z.; Yin, Q.; Huang, F.; Cao, Y. Polythiophene derivatives compatible with both fullerene and non-fullerene acceptors for polymer solar cells. J. Mater. Chem. C 2019, 7, 314-323. [CrossRef]

64. Pandey, L.; Risko, C.; Norton, J.E.; Brédas, J.-L. Donor-Acceptor Copolymers of Relevance for Organic Photovoltaics: A Theoretical Investigation of the Impact of Chemical Structure Modifications on the Electronic and Optical Properties. Macromolecules 2012, 45, 6405-6414. [CrossRef]

65. Granadino-Roldán, J.M.; Garzón, A.; García, G.; Moral, M.; Navarro, A.; Fernández-Liencres, M.P.; Peña-Ruiz, T.; Fernández-Gómez, M. Theoretical Study of the Effect of Alkyl and Alkoxy Lateral Chains on the Structural and Electronic Properties of $\pi$-Conjugated Polymers Consisting of Phenylethynyl-1,3,4-thiadiazole. J. Phys. Chem. C 2011, 115, 2865-2873. [CrossRef]

66. Risko, C.; McGehee, M.D.; Brédas, J.-L. A quantum-chemical perspective into low optical-gap polymers for highly-efficient organic solar cells. Chem. Sci. 2011, 2, 1200-1218. [CrossRef]

67. Sajid, H.; Khan, S.; Ayub, K.; Mahmood, T. High selectivity of cyclic tetrapyrrole over tetrafuran and tetrathiophene toward toxic chemicals; A first-principles study. Microporous Mesoporous Mater. 2020, 299, 110126. [CrossRef]

68. Tirado-Rives, J.; Jorgensen, W.L. Performance of B3LYP Density Functional Methods for a Large Set of Organic Molecules. J. Chem. Theory Comput. 2008, 4, 297-306. [CrossRef] [PubMed]

69. Grimme, S.; Antony, J.; Ehrlich, S.; Krieg, H. A consistent and accurate ab initio parametrization of density functional dispersion correction (DFT-D) for the 94 elements H-Pu. J. Chem. Phys. 2010, 132, 154104. [CrossRef]

70. Grimme, S.; Ehrlich, S.; Goerigk, L. Effect of the damping function in dispersion corrected density functional theory. J. Comput. Chem. 2011, 32, 1456-1465. [CrossRef]

71. Grimme, S. Density functional theory with London dispersion corrections. Wiley Interdiscip. Rev. Comput. Mol. Sci. 2011, 1, 211-228. [CrossRef]

72. Kruse, H.; Grimme, S. A geometrical correction for the inter- and intra-molecular basis set superposition error in Hartree-Fock and density functional theory calculations for large systems. J. Chem. Phys. 2012, 136, 154101. [CrossRef]

73. Torad, N.L.; Ayad, M.M. Gas Sensors Based on Conducting Polymers. In Gas Sensors; IntechOpen: London, UK, 2020.

74. Yoon, T.; Jun, J.; Kim, D.Y.; Pourasad, S.; Shin, T.J.; Yu, S.U.; Na, W.; Jang, J.; Kim, K.S. An ultra-sensitive, flexible and transparent gas detection film based on well-ordered flat polypyrrole on single-layered graphene. J. Mater. Chem. A 2018, 6, 2257-2263. [CrossRef]

75. Ullah, H.; Shah, A.-H.A.; Bilal, S.; Ayub, K. DFT Study of Polyaniline $\mathrm{NH}_{3}, \mathrm{CO}_{2}$, and CO Gas Sensors: Comparison with Recent Experimental Data. J. Phys. Chem. C 2013, 117, 23701-23711. [CrossRef]

76. Frisch, M.J.; Trucks, G.W.; Schlegel, H.B.; Scuseria, G.E.; Robb, M.A.; Cheeseman, J.R.; Scalmani, G.; Barone, V.; Petersson, G.A.; Nakatsuji, H.; et al. Gaussian16; Gaussian, Inc.: Wallingford, CT, USA, 2016.

77. Galano, A.; Alvarez-Idaboy, J.R. A new approach to counterpoise correction to BSSE. J. Comput. Chem. 2006, 27, 1203-1210. [CrossRef]

78. Sirianni, D.A.; Alenaizan, A.; Cheney, D.L.; Sherrill, C.D. Assessment of Density Functional Methods for Geometry Optimization of Bimolecular van der Waals Complexes. J. Chem. Theory Comput. 2018, 14, 3004-3013. [CrossRef] 
79. Burns, L.A.; Vázquez-Mayagoitia, A.; Sumpter, B.G.; Sherrill, C.D. Density-functional approaches to noncovalent interactions: A comparison of dispersion corrections (DFT-D), exchange-hole dipole moment (XDM) theory, and specialized functionals. J. Chem. Phys. 2011, 134, 084107. [CrossRef]

80. Zhurko, G.A.; Zhurko, D.A. Chemcraft Version 1.8. 2012. Available online: www.chemcraftprog.com (accessed on 4 August 2020).

81. Dennington, R.; Keith, T.; Millam, J.M. GaussianView6; Semichem, Inc.: Shawnee Mission, KS, USA, 2016.

82. Glendening, E.D.; Landis, C.R.; Weinhold, F. NBO 6.0: Natural bond orbital analysis program. J. Comput. Chem. 2013, 34, 1429-1437. [CrossRef] [PubMed]

83. O'boyle, N.M.; Tenderholt, A.L.; Langner, K.M. cclib: A library for package-independent computational chemistry algorithms. J. Comput. Chem. 2008, 29, 839-845. [CrossRef]

84. Dai, L. Conjugated and Fullerene-Containing Polymers for Electronic and Photonic Applications: Advanced Syntheses and Microlithographic Fabrications. J. Macromol. Sci. Part C Polym. Rev. 1999, 39, 273-387. [CrossRef]

85. Bisoi, S.; Mandal, A.K.; Padmanabhan, V.; Banerjee, S. Aromatic polyamides containing trityl substituted triphenylamine: Gas transport properties and molecular dynamics simulations. J. Membr. Sci. 2017, 522, 77-90. [CrossRef]

86. Holguín, M.; Rojas Álvarez, O.E.; Arizabaleta, C.A.; Torres, W. Molecular dynamics of the interaction of 1-tryptophan with polypyrrole oligomers. Comput. Theor. Chem. 2019, 1147, 29-34. [CrossRef]

87. Shahabi, M.; Raissi, H. Molecular dynamics simulation and quantum chemical studies on the investigation of aluminum nitride nanotube as phosgene gas sensor. J. Incl. Phenom. Macrocycl. Chem. 2016, 86, 305-322. [CrossRef]

88. Mallya, A.N.; Kottokkaran, R.; Ramamurthy, P.C. Conducting polymer-carbon black nanocomposite sensor for volatile organic compounds and correlating sensor response by molecular dynamics. Sens. Actuators B Chem. 2014, 201, 308-320. [CrossRef]

89. Yakushi, K.; Lauchlan, L.J.; Clarke, T.C.; Street, G.B. Optical study of polypyrrole perchlorate. J. Chem. Phys. 1983, 79, 4774-4778. [CrossRef]

90. Genies, E.M.; Bidan, G.; Diaz, A.F. Spectroelectrochemical study of polypyrrole films. J. Electroanal. Chem. Interfacial Electrochem. 1983, 149, 101-113. [CrossRef]

91. Nalage, S.R.; Navale, S.T.; Patil, V.B. Polypyrrole-NiO hybrid nanocomposite: Structural, morphological, optical and electrical transport studies. Measurement 2013, 46, 3268-3275. [CrossRef]

(C) 2020 by the author. Licensee MDPI, Basel, Switzerland. This article is an open access article distributed under the terms and conditions of the Creative Commons Attribution (CC BY) license (http://creativecommons.org/licenses/by/4.0/). 